Article

\title{
Socioeconomic Status and Self-Rated Oral Health; Diminished Return among Hispanic Whites
}

\author{
Shervin Assari 1,2 (iD) \\ 1 Center for Research on Ethnicity, Culture, and Health (CRECH), School of Public Health, University of \\ Michigan, Ann Arbor 48109-2700, MI, USA; assari@umich.edu \\ 2 Department of Psychiatry, University of Michigan, Ann Arbor 48109-2700, MI, USA 4250 Plymouth Rd., \\ Ann Arbor, MI 48109-2700, USA
}

Received: 18 March 2018; Accepted: 20 April 2018; Published: 24 April 2018

\begin{abstract}
Background. An extensive body of knowledge has documented weaker health effects of socio-economic status (SES) for Blacks compared to Whites, a phenomenon also known as Blacks' diminished return. It is, however, unknown whether the same diminished return also holds for other ethnic minorities such as Hispanics or not. Aim. Using a nationally representative sample, the current study aimed to compare Non-Hispanic and Hispanic Whites for the effects of SES on self-rated oral health. Methods. For the current cross-sectional study, we used data from the Collaborative Psychiatric Epidemiology Surveys (CPES), 2001-2003. With a nationally representative sampling, CPES included 11,207 adults who were either non-Hispanic Whites $(n=7587)$ or Hispanic Whites ( $n=3620$. The dependent variable was self-rated oral health, treated as dichotomous measure. Independent variables were education, income, employment, and marital status. Ethnicity was the focal moderator. Age and gender were covariates. Logistic regressions were used for data analysis. Results. Education, income, employment, and marital status were associated with oral health in the pooled sample. Although education, income, employment, and marital status were associated with oral health in non-Hispanic Whites, none of these associations were found for Hispanic Whites. Conclusion. In a similar pattern to Blacks' diminished return, differential gain of SES indicators exists between Hispanic and non-Hispanic Whites, with a disadvantage for Hispanic Whites. Diminished return of SES should be regarded as a systemically neglected contributing mechanism behind ethnic oral health disparities in the United States. Replication of Blacks' diminished return for Hispanics suggests that these processes are not specific to ethnic minority groups, and non-White groups gain less because they are not enjoying the privilege and advantage of Whites.
\end{abstract}

Keywords: economic inequalities; ethnic health disparities; socioeconomic status; oral health

\section{Introduction}

Ethnic disparities in oral health have been well-established in several studies, with Hispanics and Blacks being at higher risk of poor oral health $[1,2]$. Hispanics generally have poorer oral health compared to non-Hispanic Whites in the United States. For instance, Hispanic Whites aged 35-44 years are twice as likely to have an untreated tooth decay compared to non-Hispanic Whites, which is mainly due to lower access of minority and low socioeconomic status (SES) individuals to dental care [1]. A major explanation for ethnic disparities in oral health is lower SES status of ethnic minority populations [2-9].

Socioeconomic status indicators such as education attainment and income are protective factors against poor oral health and enhances population access to oral health care services [10-12]. Among adults aged 35-44 years, having less than a high school education is associated with three-fold increase in untreated tooth decay in comparison to the individuals having some college education. Individuals 
with less than a high school education are three times more likely to have destructive periodontal (gum) disease compared to individuals with some college education [1]. Various barriers reduce dental health care use of low educated and low-income individuals including low levels of oral health literacy, not seeing oral health as a major component of overall health, and lower access to oral health care services [2].

Income inequalities are probably the largest contributors to oral health disparities [13]. Low-income reduces the chance of having seen a dental provider over the past year [14]. In 2010, annual dental visits were $42 \%$ and $70 \%$ in individuals above and below $200 \%$ of the federal poverty line [14]. One fifth of low-income adults report no dental visit in the past five years [14]. Several barriers including insurance, transportation, and time flexibility hinder low income individuals from chance of having a dental visit [2].

Unequal gain of equal resources is a systemically neglected cause of health disparities [15]. Different from other explanations such as poor access to the healthcare system [16], low SES [17], high stress [18], and discrimination in the community [19] and health care system [16], minorities diminished return argues that some of the ethnic health disparities are not because of lower SES of ethnic minorities, but lower health gain that follows the very same SES indicators such as education, income, employment, and marital status [15,20].

Aim

Using a nationally representative sample of non-Hispanic and Hispanic Whites, the current study aimed to explore ethnic variation in the effects of SES on self-rated oral health. In line with the Blacks' diminished return theory, we expected education, income, employment, and marital status to be associated with oral health in overall sample. We, however, expected stronger protective effects of SES indicators against poor oral health for non-Hispanic and Hispanic Whites.

\section{Methods}

\subsection{Design and Setting}

With a cross-sectional design, the current study used data from the Collaborative Psychiatric Epidemiology Surveys (CPES), 2001-2003. The CPES was conducted by the University of Michigan (UM). Although the CPES methods has been described in detail elsewhere [21], we briefly summarize the study methodology here.

CPES is composed of three national surveys: (1) the National Comorbidity Survey-Replication (NCS-R) [22]; (2) the National Latino and Asian American Study (NLAAS) [23]; and (3) the National Study of American Life (NSAL) [21]. The CPES data were collected by the University of Michigan (UM) Institute for Social Research (ISR), Ann Arbor.

\subsection{Sampling}

Non-Hispanic White and Hispanic White participants were recruited using the CPES core sampling. Core sampling of the CPES was a multistage stratified area probability sample, that recruited a nationally representative household sample. All participants were adults (18 years of age and older). Participants were recruited from households in the coterminous 48 states. The sample was limited to individuals who were able to conduct an interview in English. This study did not include any institutionalized individual. Thus, being in prisons, jails, nursing homes, and medical facilities were exclusion criteria [21]. Non-Hispanic White and Hispanic White in the CPES were selected from large cities, other urban areas, or rural areas [21]. The analysis for the current study included a total of 11,207 adults who were either non-Hispanic Whites $(n=7587)$ or Hispanic Whites $(n=3620)$. 


\subsection{Ethics}

The CPES study protocol was approved by the University of Michigan (UM) Institutional Review Board (IRB \# B03-00004038-R1). Informed written consent was received from all the participants. Data were kept anonymous. Participants were financially compensated for their time. Publicly available CPES data were downloaded from Interuniversity Consortium for Political and Social Research (ICPSR https:/ / www.icpsr.umich.edu), located at University of Michigan (UM) Institute for Social Research (ISR).

\subsection{Data Collection}

CPES collected data using structured interviews (survey questionnaires). Most of the data were collected using computer-assisted face-to-face interviews. Telephone interviews were only used for the remaining of the data collection. Interviews lasted between 2 and two hours on average. The overall response rate of the CPES is $69 \%$.

\subsection{Measures}

\subsubsection{Independent Variables}

Household income was self-reported. Income was treated as a continuous measure in this study. To increase interpretability of the income coefficients, we divided income by USD 10,000. So, our income coefficients reflect the effect of a USD 10,000 increase in income on odds of poor self-rated oral health. The socioeconomic covariate included education, which was measured as an ordinal variable with the following four categories: (1) less than 11 years; (2) 12 years; (3) between 13 and 15 years; and (4) 16 years or more. Education was operationalized as a continuous variable.

\subsubsection{Dependent Variable}

Self-rated Oral Health. A single item measure was used for oral health. The item was "How would you rate the overall condition of your teeth, gums, and mouth at the present time?" Responses were (1) Excellent; (2) Very good; (3) Good; (4) Fair; and (5) Poor. The findings suggest that perceived oral health may be a useful outcome measure in dentistry because of its relation to predisposing socio-demographics and dental utilization [24]. Regardless of ethnicity, self-rated oral health reflects oral symptoms [24]. We considered fair/poor oral health as the outcome, with other responses (excellent, very good, good) as the reference group [25].

\subsubsection{Covariates}

Covariates in this study included demographic characteristics (age and gender). Age was operationalized as a continuous variable. Gender was conceptualized as a dichotomous variable (male 1 vs. female 0 ).

\subsubsection{Moderator}

Ethnicity. Ethnicity was self-identified in the CPSE [26-32]. Hispanic Whites were defined as persons who were of Latino, Hispanic or Spanish origin and were not Blacks. Ethnicity was treated as a dichotomous variable, with non-Hispanic Whites being the reference category. (Hispanic Whites $=1$ vs. non-Hispanic Whites $=0$ ). Hispanic Whites were composed of from four distinct ethnic subgroups: 868 Mexican, 577 Cuban, 495 Puerto Ricans and 614 Other Latinos.

\subsection{Statistical Analysis}

\subsubsection{Weights}

To accommodate the CPES's sampling weight due to the multi-stage sampling design, we used Stata 13.0 (Stata Corp., College Station, TX, USA) for all our data analysis. This approach will generate 
nationally representative statistics. Taylor series linearization was used to estimate designed based standard errors and variances. To perform our subsample analyses, we applied sub-pop survey commands in Stata.

\subsubsection{Analytical Plan}

For descriptive purposes, we used mean (SE) and proportions (relative frequency). Bivariate analyses included independent sample $t$ test, Pearson Chi square, and Spearman correlation tests in the pooled sample and by ethnicity. For multivariable analysis, we used logistic regression models. Adjusted odds ratios (OR) and $p$ values were reported. In our logistic regression models, SES indicators were the independent variables, poor self-rated oral health was the dependent variable, and demographics were covariates. Ethnicity was the focal moderator. The first series of logistic regression models (Model 1) estimated the main effects of ethnicity and SES indicators in the pooled sample. Next models (Model 2) included one ethnicity by SES interaction term. Then we ran subsequent models in non-Hispanic Whites (Model 3) and Hispanic Whites (Model 4).

\section{Results}

\subsection{Descriptive Statistics}

Table 1 describes the descriptive statistics for the pooled sample as well as non-Hispanic and Hispanic Whites. Gender was not different in Non-Hispanic and Hispanic Whites. Non-Hispanic Whites were considerably older than Hispanic Whites. Compared to non-Hispanic Whites, Hispanic Whites had lower educational attainment and income. Hispanic Whites were less likely to be married and employed than non-Hispanic Whites.

Table 1. Descriptive statistics in the pooled sample and based on ethnicity.

\begin{tabular}{|c|c|c|c|}
\hline Characteristics & All & Non-Hispanic Whites & Hispanic Whites \\
\hline & $\%$ & $\%$ & $\%$ \\
\hline \multicolumn{4}{|l|}{ Gender } \\
\hline Male & 52.79 & 52.78 & 53.16 \\
\hline Female & 47.21 & 47.22 & 46.84 \\
\hline \multicolumn{4}{|l|}{ Employed * } \\
\hline No & 27.00 & 26.76 & 34.22 \\
\hline Yes & 73.00 & 73.24 & 65.78 \\
\hline \multicolumn{4}{|l|}{ Married * } \\
\hline No & 46.19 & 45.82 & 57.07 \\
\hline Yes & 53.81 & 54.18 & 42.93 \\
\hline \multicolumn{4}{|l|}{ Poor Dental Health * } \\
\hline No & 90.48 & 90.35 & 94.44 \\
\hline \multirow[t]{2}{*}{ Yes } & 9.52 & 9.65 & 5.56 \\
\hline & Mean & Mean & Mean \\
\hline Age * & 44.86 & 46.73 & 37.96 \\
\hline Education* & 2.56 & 2.69 & 1.97 \\
\hline Household Income (USD 10,000) * & 5.72 & 6.17 & 4.45 \\
\hline
\end{tabular}

\subsection{Bivariate Correlations}

Table 2 presents the results of bivariate correlations in the pooled sample. SES indicators including education, income, marital status and employment were correlated with self-rated oral health in the pooled sample (Table 2). 
Table 2. Spearman correlations in the pooled sample.

\begin{tabular}{|c|c|c|c|c|c|c|c|c|}
\hline Characteristics & 1 & 2 & 3 & 4 & 5 & 6 & 7 & 8 \\
\hline 1 Ethnicity (Hispanic Whites) & 1.00 & & & & & & & \\
\hline 2 Gender (Men) & 0.03 & 1.00 & & & & & & \\
\hline 3 Age & $-0.14^{*}$ & -0.02 & 1.00 & & & & & \\
\hline 4 Education & -0.05 & 0.00 & $-0.12 *$ & 1.00 & & & & \\
\hline 5 Household Income (USD 10,000) & -0.05 & $0.14 *$ & $-0.08^{*}$ & 0.35 * & 1.00 & & & \\
\hline 6 Employment (Employed) & -0.03 & $0.09 *$ & $-0.40 *$ & 0.28 * & 0.30 * & 1.00 & & \\
\hline 7 Marital Status (Married) & -0.03 & 0.16 * & -0.06 & 0.02 & $0.38^{*}$ & $0.12 *$ & 1.00 & \\
\hline 8 Self-Rated Oral Health (Poor / fair) & -0.03 & -0.01 & $0.10 *$ & $-0.17^{*}$ & $-0.15 *$ & $-0.17^{*}$ & $-0.09 *$ & 1.00 \\
\hline
\end{tabular}

\subsection{Logistic Regressions in the Pooled Sample}

Table 3 presents the results of two series of logistic regression models in the pooled sample with oral health as the outcome. Model 1 only included the main effects of ethnicity and SES. Model 2 also included an interaction term between ethnicity and a SES indicator. Based on Model 1, education, income, employment, and marital status were associated with oral health in the pooled sample. (Table 3).

Table 3. Summary of logistic regressions between SES (education, income, employment, and marital status) and poor self-rated mental health (SRH) in the pooled sample.

\begin{tabular}{lcccc}
\hline \multirow{2}{*}{ Characteristics } & OR & OR & OR & OR \\
\cline { 2 - 5 } & Education & Income & Employment & Marital Status \\
\hline Education & & & & \\
Ethnicity (Hispanic Whites) & $0.56^{*}$ & $0.49^{*}$ & $0.52^{*}$ & $0.64^{*}$ \\
Gender (Men) & $1.69^{*}$ & $2.35^{*}$ & $2.07^{*}$ & $1.89^{*}$ \\
Age & $1.02^{*}$ & $1.02^{*}$ & $1.01^{*}$ & $1.02^{*}$ \\
SES & $0.57^{*}$ & $0.65^{*}$ & $0.28^{*}$ & $0.47^{*}$ \\
Intercept & $0.15^{*}$ & $0.13^{*}$ & $0.12 *$ & $0.04^{*}$ \\
\hline Income & & & & $0.37^{*}$ \\
Ethnicity (Hispanic Whites) & $0.53^{*}$ & $0.10^{*}$ & $0.43^{*}$ & $1.89^{*}$ \\
Gender (Men) & $1.69^{*}$ & $2.36^{*}$ & $2.07^{*}$ & $1.02^{*}$ \\
Age & $1.02^{*}$ & $1.02^{*}$ & $1.01 *$ & $0.46^{*}$ \\
SES & 0.57 & $0.63^{*}$ & $0.28^{*}$ & $3.37^{*}$ \\
SES Ethnicity & $1.02^{*}$ & $1.68^{*}$ & $1.55^{*}$ & $0.04^{*}$ \\
Intercept & $0.15^{*}$ & $0.14^{*}$ & $0.13^{*}$ & \\
\hline
\end{tabular}

OR: Odds Ratio. SES (Socioeconomic Status). ${ }^{*} p<0.05$.

\subsection{Logistic Regressions in Non-Hispanic Whites, Hispanic Whites}

Based on Model 3, education, income, employment, and marital status were associated with oral health in non-Hispanic Whites. Based on Model 4, education, income, employment, and marital status were not associated with oral health in Hispanic Whites (Table 4). 
Table 4. Summary of logistic regressions between SES (education, income, employment, and marital status) and poor oral self-rated health (SRH) in non-Hispanic and Hispanic Whites.

\begin{tabular}{ccccc}
\hline & OR & OR & OR & OR \\
\cline { 2 - 4 } & Education & Income & Employment & Marital Status \\
\hline Model 3 & & & \\
\hline Non-Hispanic Whites & & & \\
Gender (Women) & 1.76 & $2.50^{*}$ & $2.17^{*}$ & 1.98 \\
Age & 1.01 & 1.02 & 1.00 & 1.02 \\
SES & $0.57^{*}$ & $0.63^{* * *}$ & $0.27^{*}$ & $0.45^{*}$ \\
Intercept & 0.15 & $0.13^{*}$ & 0.13 & $0.04^{* *}$ \\
\hline Model 4 & & & \\
Hispanic Whites & & & \\
Gender (Women) & $0.18 *$ & $0.11^{*}$ & $0.15 *$ & $1.05^{* * *}$ \\
Age & $1.04^{*}$ & $1.04^{* *}$ & $1.04^{*}$ & 3.17 \\
SES & 0.71 & 1.14 & 0.76 & $0.01^{* * *}$ \\
Intercept & $0.05^{*}$ & $0.01^{* * *}$ & $0.03^{*}$ &
\end{tabular}

\section{Discussion}

The current study was conducted with two aims: First, to test the association between SES and self-rated oral health in overall sample. Second, to compare non-Hispanic Whites and Hispanic Whites for the effects of SES on self-rated oral health. Our first finding suggested that education, income, marital status, and employment are associated with better self-rated oral health. Our second finding showed that all these SES indicators better protect non-Hispanic Whites than Hispanic Whites.

The first finding is in line with extensive theoretical and empirical work on fundamental causes [33] and social determinant [34-36]. Social patterning of oral health is in line with social gradient in other health domains. Most outcomes in health are socially patterned, and oral health is not an exception to this rule. Low income, low education, and unemployment reduce health [37]. This is shown across cohorts, settings, and follow up durations [38-43].

Economic resources such as employment and income are essential for maintaining health [33]. Not only high SES reduces individuals' exposure to risk factors of tooth decay and poor oral health [44], employment and income increase population to preventive dental care [44-47]. This is particularly true for United States where employment is the gatekeeper to insurance [48]. As dental care is expensive, poor and unemployed individuals face major difficulty for maintaining oral health [49].

The second finding is in line with previous research that has shown equal resources result in unequal gain across ethnic groups, with disproportionately larger gains for Whites than minorities [50-54]. Most of the literature, however, is generated from comparison of Blacks and Whites, also known as Blacks diminished return hypothesis [20]. In NSAL data, SES protected individuals against poor oral health, however, these protective effects were larger for Whites than Blacks [55]. In another study, family SES (living out of poverty) had a stronger effect on dental health care use in Whites than Black children [56].

Research, however, is mostly on Blacks than other ethnic groups. In a study, education and income result in larger health gain across domains for Whites compared to Blacks [57], patterns that are similar for young people [58], adults [59] and older adults [60]. The effects of education [59], employment [60], social contacts [61], self-efficacy [62], sense of control over life [63], neighborhood quality [64], and affect [65] on mortality all are shown to be larger for Whites than for Blacks. So, SES may not be the great equalizer of ethnic groups [66]. 
It seems that Blacks' diminished return [20] is a part of a more general broad pattern on minorities diminished return [15]. This suggests that it is ethnicity and SES not ethnicity or SES that cause health disparities [67].

The results of this study contribute to our understanding of causes of health disparities. Although some of the minorities' worse health outcomes are due to lower SES that shape their resources (Differential exposures), SES disproportionately better serves the majority group than the minority populations (Differential effects). So, SES may better help the privileged group to avoid risk and minimize subsequent negative consequences of exposures and illness [68].

The message of this paper for policy makers, public health officials, and clinicians is that they should not assume that promotion of access to socioeconomic resources will similarly enhance the health of all social groups. Risk factors, protective factors, and group membership interact on health [67]. Policy makers should be aware that demographic populations with same SES will have various levels of health. Researchers should also explore interactions between ethnicity, and SES on health outcomes $[69,70]$. Due to a diminished return among Blacks, it is plausible to expect wide ethnic disparities at the highest levels of SES [71]. However, it is always difficult to decompose the effects of ethnicity and SES on health [72]. Due to residual and unmeasured confounding variables and considerable overlap between race and SES, more research is needed on how ethnicity impacts health [73]. Such research should also include higher level factors such as neighborhood SES and policy.

Oral health is sensitive to health behaviors from childhood [74,75]. Ethnic minorities who are able to climb the social ladder may still have spent childhood in poverty. When they were children, the unemployment, low income, and low education of parents has already taken their toll from their oral health. Minorities are more recent to middle class, that means they are more likely to have lower SES parents. Oral health may be a lower priority for low SES families, particularly those who are struggling with economic hardships and other medical needs $[49,76,77]$. Oral health literacy is a function of SES and ethnicity $[78,79]$. All these may suggest why high SES minorities may have worse oral health than high SES Whites.

\subsection{Limitations}

Current study had several limitations that limit applicability and generalizability of the results. First and foremost, this was a cross-sectional study and the results should not be regarded as causations. Second, oral health was measured using self-rated single item measure, that has limited validity. This can become a problem if the validity of such measure if a function of ethnicity. Although self-rated oral health is linked to other measures such as dental health care utilization and dental health care need, these associations are not very strong. Third, the study did not measure any mechanism for differential effects of education and income on oral health. Furthermore, the data used for this study were collected in 2003. Although the data were old, the recent political climate in United States, which has wakened the hidden racism against minorities and immigrants, may have increased the diminished return of ethnic minorities from their SES resources. Fourth, the current data were collected via face-to-face household interviews and telephone interviews. Mode of the interview may have some impact in health surveys. Only a minority (less than $20 \%$ ) of the interviews, however, were conducted via phone. Sampling bias may also be a problem as some individuals could not be contacted by phone and could only undergo the face-to face-interview. Finally, the survey used for the current analysis was from 2003. Inequalities in SES as well as oral health and may have changed since then. There is a need to replicate the inequalities and gradients in oral health that were reported here in more recent US nationally representative surveys. Despite these limitations, large sample size, and nationally representative sample were two major advantages of the current study.

\subsection{Future Research}

Research is also needed on contribution of the education system, labor market, segregation, and access to care in shaping differential effects of SES on oral health of ethnic groups. There is also a 
need to ascertain the most effective public and health policies that minimize health disparities due to diminished gain among ethnic minorities. As the mechanisms that cause oral health disparity are multifaceted, the required research should consider inputs from public policy, economics, health policy, psychology, anthropology, sociology, epidemiology, dentistry, and public health. Future research may focus on cultural, social, and community level factors that impact these diminished gains [80-86]. More research is also required in an individual level, on how coping, literacy, and individual behaviors explain the differential effects of SES on oral health of populations.

Future research also needs to explore the role of smoking, oral health care, and obesity, that are linked with periodontal disease, as potential mechanism for differential effects of SES. SES, chronic disease, and periodontal conditions are all linked, thus future needs to test the role of chronic disease in diminished oral health of high SES Latinos. Future research should go beyond self-rated oral health and test oral diseases by the intersection of race and class. Future research should also include clinical examination and more detailed oral health data. National surveys such as the National Health and Nutrition Examination Survey (NHANES) data that collect detailed information on oral health are useful source for future research. Such studies may decompose the effects of race and class in shaping burden of oral health disparities [87-89].

\subsection{Conclusions}

To conclude, SES is protective against poor oral health overall, however, non-Hispanic Whites gain more oral health from their SES than Hispanic Whites. Role of diminished return of SES as a contributing mechanism behind ethnic health disparities should not be overlooked.

Acknowledgments: This research is supported by National Institute of Mental Health Research Grants MH06220, MH62207, MH62209, HD049142 and RWJ DA18715 with generous support from SAMHSA and OBSSR. The National Survey of American Life (NSAL) was supported by the National Institute of Mental Health (U01-MH57716) with supplemental support from the National Institutes of Health Office of Behavioral and Social Science Research; National Institute on Aging (5R01 AG02020282) with supplemental support from the National Institute on Drug Abuse; and the University of Michigan. Preparation of this article was also aided by grants from the National Institute of Mental Health (1P01 MH58565, 1T32 MH67555, and 5TMH16806). This publication was also made possible by Grant Number 1KL2RR025015-01 from the National Center for Research Resources (NCRR), a component of the National Institutes of Health (NIH) and NIH Roadmap for Medical Research. Publicly available data was used for this paper. Data were downloaded from the Inter-University Consortium for Political and Social Research (ICPSR), University of Michigan, Ann Arbor. Shervin Assari is supported by the Heinz C. Prechter Bipolar Research Fund and the Richard Tam Foundation at the University of Michigan Depression Center.

Conflicts of Interest: The authors declare no conflict of interest.

\section{References}

1. Centers for Disease Control and Prevention (CDC). Oral Health Disparities. 2016. Available online: https: //www.cdc.gov/oralhealth/oral_health_disparities/index.htm (accessed on 1 April 2018).

2. U.S. Dept. of Health and Human Services. Oral Health in America: A Report of the Surgeon General; National Institute of Dental and Craniofacial Research, National Institutes of Health: Bethesda, MD, USA, 2000.

3. Dietrich, T.; Culler, C.; Garcia, R.I.; Henshaw, M.M. Racial and ethnic disparities in children's oral health: The National Survey of Children's Health. J. Am. Dent. Assoc. 2008, 139, 1507-1517. [CrossRef] [PubMed]

4. Flores, G.; Tomany-Korman, S.C. Racial and ethnic disparities in medical and dental health, access to care, and use of services in US children. Pediatrics 2008, 121, e286-e298. [CrossRef] [PubMed]

5. Flores, G.; Tomany-Korman, S.C. The language spoken at home and disparities in medical and dental health, access to care, and use of services in US children. Pediatrics 2008, 121, e1703-e1714. [CrossRef] [PubMed]

6. Edelstein, B.L.; Chinn, C.H. Update on disparities in oral health and access to dental care for America's children. Acad. Pediatr. 2009, 9, 415-419. [CrossRef] [PubMed]

7. Andersen, R.M.; Davidson, P.L. Ethnicity, aging, and oral health outcomes: A conceptual framework. Adv. Dent. Res. 1998, 11, 203-209. [CrossRef] [PubMed]

8. Edelstein, B.L. Disparities in oral health and access to care: Findings of national surveys. Ambul. Pediatr. 2002, 2, 141-147. [CrossRef] 
9. Atchison, K.A.; Der-Martirosian, C.; Gift, H.C. Components of Self-reported Oral Health and General Health in Racial and Ethnic Groups. J. Public Health Dent. 1998, 58, 301-308. [CrossRef] [PubMed]

10. Geyer, S.; Schneller, T.; Micheelis, W. Social gradients and cumulative effects of income and education on dental health in the Fourth German Oral Health Study. Commun. Dent. Oral Epidemiol. 2010, 38, 120-128. [CrossRef] [PubMed]

11. Durey, A.; Bessarab, D.; Slack-Smith, L. The mouth as a site of structural inequalities; the experience of Aboriginal Australians. Commun. Dent Health 2016, 33, 161-163.

12. Herkrath, F.J.; Vettore, M.V.; Werneck, G.L. Contextual and individual factors associated with dental services utilisation by Brazilian adults: A multilevel analysis. PLoS ONE 2018, 13, e0192771. [CrossRef] [PubMed]

13. Kaiser Family Foundation. Medicaid Kaiser Commission o n P O L I C Y B R I E F and the Uninsured. Oral Health and Low-Income Nonelderly Adults: A Review of Coverage and Access. 2012. Available online: https:/ / kaiserfamilyfoundation.files.wordpress.com/2013/03/7798-02.pdf (accessed on 1 April 2018).

14. NHIS. Data Release. 2010. Available online: https://www.cdc.gov/nchs/nhis/data-questionnairesdocumentation.htm (accessed on 1 April 2018).

15. Assari, S. Unequal gain of equal resources across racial groups. Int. J. Health Policy Manag. 2017, 6, 1-6. [CrossRef] [PubMed]

16. Nelson, A.R.; Stith, A.Y.; Smedley, B.D. (Eds.) Unequal Treatment: Confronting Racial and Ethnic Disparities in Health Care (Full Printed Version); National Academies Press: Washington, DC, USA, 2002.

17. LaVeist, T.A. Disentangling race and socioeconomic status: A key to understanding health inequalities. J. Urban Health 2005, 82, iii26-iii34. [CrossRef] [PubMed]

18. Lantz, P.M.; House, J.S.; Mero, R.P.; Williams, D.R. Stress, life events, and socioeconomic disparities in health: Results from the Americans' Changing Lives Study. J. Health Soc. Behav. 2005, 46, 274-288. [CrossRef] [PubMed]

19. Williams, D.R.; Neighbors, H.W.; Jackson, J.S. Racial/ethnic discrimination and health: Findings from community studies. Am. J. Public Health 2003, 93, 200-208. [CrossRef] [PubMed]

20. Assari, S. Health Disparities Due to Diminished Return among Black Americans: Public Policy Solutions. Soc. Issues Policy Rev. 2018, in press. [CrossRef]

21. Heeringa, S.; Wagner, J.; Torres, M.; Duan, N.H.; Adams, T.; Berglund, P. Sample designs and sampling methods for the collaborative psychiatric epidemiology studies (CPES). Int. J. Methods Psychiatr. Res. 2004, 13, 221-240. [CrossRef] [PubMed]

22. Kessler, R.C.; Merikangas, K.R. The National Comorbidity Survey Replication (NCS-R): Background and aims. Int. J. Methods Psychiatr. Res. 2004, 13, 60-68. [CrossRef] [PubMed]

23. Alegria, M.; Takeuchi, D.; Canino, G.; Duan, N.; Shrout, P.; Meng, X.; Vega, W.; Zane, N.; Vila, D.; Woo, M.; et al. Considering context, place and culture: The National Latino and Asian American Study. Int. J. Methods Psychiatr. Res. 2004, 13, 208-220. [CrossRef] [PubMed]

24. Atchison, K.A.; Gift, H.C. Perceived oral health in a diverse sample. Adv. Dent. Res. 1997, 11, $272-280$. [CrossRef] [PubMed]

25. Assari, S.; Lankarani, M.M.; Burgard, S.A. Black White difference in long term predictive power of self-rated health on all-cause mortality in United States. Ann. Epidemiol. 2016, 26, 106-114. [CrossRef] [PubMed]

26. Spencer, E.A.; Appleby, P.N.; Davey, G.K.; Key, T.J. Validity of self-reported height and weight in 4808 EPIC-Oxford participants. Public Health Nutr. 2002, 5, 561-565. [CrossRef] [PubMed]

27. Stewart, A.L. The reliability and validity of self-reported weight and height. J. Chronic Dis. 1982, 35, $295-309$. [CrossRef]

28. Mericle, A.A.; Ta Park, V.M.; Holck, P.; Arria, A.M. Prevalence, patterns, and correlates of co-occurring substance use and mental disorders in the United States: Variations by race/ethnicity. Compr. Psychiatry 2012, 53, 657-665. [CrossRef] [PubMed]

29. Chou, T.; Asnaani, A.; Hofmann, S.G. Perception of racial discrimination and psychopathology across three U.S. ethnic minority groups. Cult. Divers. Ethn. Minor. Psychol. 2012, 18, 74-81. [CrossRef] [PubMed]

30. Asnaani, A.; Richey, J.A.; Dimaite, R.; Hinton, D.E.; Hofmann, S.G. A cross-ethnic comparison of lifetime prevalence rates of anxiety disorders. J. Nerv. Ment. Dis. 2010, 198, 551-555. [CrossRef] [PubMed]

31. Asnaani, A.; Gutner, C.A.; Hinton, D.E.; Hofmann, S.G. Panic disorder, panic attacks and panic attack symptoms across race-ethnic groups: Results of the collaborative psychiatric epidemiology studies. CNS Neurosci. Ther. 2009, 15, 249-254. [CrossRef] [PubMed] 
32. Gavin, A.R.; Walton, E.; Chae, D.H.; Alegria, M.; Jackson, J.S.; Takeuchi, D. The associations between socio-economic status and major depressive disorder among Blacks, Latinos, Asians and non-Hispanic Whites: Findings from the Collaborative Psychiatric Epidemiology Studies. Psychol. Med. 2010, 40, 51-61. [CrossRef] [PubMed]

33. Link, B.; Phelan, J. Social conditions as fundamental causes of disease. J. Health Soc. Behav. 1995, 36, 80-94. [CrossRef]

34. WHO Commission on Social Determinants of Health, \& World Health Organization. Closing the Gap in a Generation: Health Equity through Action on the Social Determinants of Health: Commission on Social Determinants of Health Final Report; World Health Organization: Geneva, Switzerland, 2008.

35. Marmot, M. The Health Gap: The Challenge of an Unequal World; Bloomsbury Publishing: London, UK, 2015.

36. Marmot, M.; Allen, J.; Bell, R.; Goldblatt, P. Building of the global movement for health equity: From Santiago to Rio and beyond. Lancet 2012, 379, 181-188. [CrossRef]

37. Patrick, D.L.; Lee, R.S.; Nucci, M.; Grembowski, D.; Jolles, C.Z.; Milgrom, P. Reducing oral health disparities: A focus on social and cultural determinants. BMC Oral Health 2006, 6, S4. [CrossRef] [PubMed]

38. Bowen, M.E.; González, H.M. Childhood socioeconomic position and disability in later life: Results of the health and retirement study. Am. J. Public Health 2010, 100, S197-S203. [CrossRef] [PubMed]

39. Leopold, L.; Engelhartdt, H. Education and physical health trajectories in old age. Evidence from the Survey of Health, Ageing and Retirement in Europe (SHARE). Int. J. Public Health 2013, 58, 23-31. [CrossRef] [PubMed]

40. Herd, P.; Goesling, B.; House, J.S. Socioeconomic position and health: The differential effects of education versus income on the onset versus progression of health problems. J. Health Soc. Behav. 2007, 48, $223-238$. [CrossRef] [PubMed]

41. Gueorguieva, R.; Sindelar, J.L.; Falba, T.A.; Fletcher, J.M.; Keenan, P.; Wu, R.; Gallo, W.T. The impact of occupation on self-rated health: Cross-sectional and longitudinal evidence from the health and retirement survey. J. Gerontol. Ser. B Psychol. Sci. Soc. Sci. 2009, 64, 118-124. [CrossRef] [PubMed]

42. Hummer, R.A.; Rogers, R.G.; Nam, C.B.; Ellison, C.G. Religious involvement and U.S. adult mortality. Demography 1999, 36, 273-285. [CrossRef] [PubMed]

43. McDonough, P.; Williams, D.R.; House, J.S.; Duncan, G.J. Gender and the socioeconomic gradient in mortality. J. Health Soc. Behav. 1999, 40,17-31. [CrossRef] [PubMed]

44. Watt, R.; Sheiham, A. Inequalities in oral health: A review of the evidence and recommendations for action. Br. Dent. J. 1999, 187, 6-12. [CrossRef] [PubMed]

45. Devaux, M. Income-related inequalities and inequities in health care services utilisation in 18 selected OECD countries. Eur. J. Health Econ. 2015, 16, 21-33. [CrossRef] [PubMed]

46. Manski, R.J.; Magder, L.S. Demographic and socioeconomic predictors of dental care utilization. J. Am. Dent. Assoc. 1998, 129, 195-200. [CrossRef] [PubMed]

47. Locker, D.; Maggirias, J.; Quiñonez, C. Income, dental insurance coverage, and financial barriers to dental care among Canadian adults. J. Public Health Dent. 2011, 71, 327-334. [CrossRef] [PubMed]

48. Smith, J.C.; Medalia, C. Health Insurance Coverage in the United States: 2013; US Department of Commerce, Economics and Statistics Administration, Bureau of the Census: Washington, DC, USA, 2014.

49. Mouradian, W.E.; Wehr, E.; Crall, J.J. Disparities in children's oral health and access to dental care. JAMA 2000, 284, 2625-2631. [CrossRef] [PubMed]

50. Assari, S. Combined racial and gender differences in the long-term predictive role of education on depressive symptoms and chronic medical conditions. J. Racial Ethn. Health Disparities 2017, 4, 385-396. [CrossRef] [PubMed]

51. Assari, S. Ethnic and gender differences in additive effects of socio-economics, psychiatric disorders, and subjective religiosity on suicidal ideation among blacks. Int. J. Prev. Med. 2015, 6, 53. [CrossRef] [PubMed]

52. Assari, S.; Caldwell, C.H. High risk of depression in high income African American boys. J. Racial Ethn. Health Disparities 2017. [CrossRef] [PubMed]

53. Assari, S. Social Determinants of Depression: The Intersections of Race, Gender, and Socioeconomic Status. Brain Sci. 2017, 7, 156. [CrossRef] [PubMed]

54. Assari, S. The Benefits of Higher Income in Protecting against Chronic Medical Conditions Are Smaller for African Americans than Whites. Healthcare 2018, 6, 2. [CrossRef] [PubMed] 
55. Assari, S. Education and Income Generate Less Oral Health for Blacks than Whites; Blacks' Diminished Return Explains Oral Health Disparities in United States. Front. Psychol. 2018. under review.

56. Assari, S.; Hani, N. Family Socioeconomic Status and Children's Unmet Dental Care; Blacks' Diminished Return in A National Sample. 2018; under review.

57. Assari, S.; Nikahd, A.; Malekahmadi, M.R.; Lankarani, M.M.; Zamanian, H. Race by gender group differences in the protective effects of socioeconomic factors against sustained health problems across five domains. J. Racial Ethn. Health Disparities 2016. [CrossRef] [PubMed]

58. Assari, S.; Thomas, A.; Cadlwell, C.; Mincy, R. Blacks' Diminished Health Return of Family Structure and Socioeconomic Status; 15 Years of Follow-up of a National Urban Sample of Youth. J. Urban Health 2017, 95, 21-35. [CrossRef] [PubMed]

59. Assari, S.; Lankarani, M.M. Race and urbanity alter the protective effect of education but not income on mortality. Front. Public Health 2016, 4, 100. [CrossRef] [PubMed]

60. Assari, S. Life expectancy gain due to employment status depends on race, gender, education, and their intersections. J. Racial Ethn. Health Disparities 2017. [CrossRef] [PubMed]

61. Assari, S. Whites but not Blacks gain life expectancy from social contacts. Behav. Sci. 2017, 7, 68. [CrossRef] [PubMed]

62. Assari, S. General self-efficacy and mortality in the USA; Racial differences. J. Racial Ethn. Health Disparities 2017, 4, 746-757. [CrossRef] [PubMed]

63. Assari, S. Race, sense of control over life, and short-term risk of mortality among older adults in the United States. Arch. Med. Sci. 2017, 13, 1233-1240. [CrossRef] [PubMed]

64. Assari, S. Perceived neighborhood safety better predicts 25-year mortality risk among whites than blacks. J. Racial Ethn. Health Disparities 2016. [CrossRef]

65. Assari, S. Hostility, anger, and cardiovascular mortality among blacks and whites. Res. Cardiovasc. Med. 2016. [CrossRef]

66. Holmes, C.J.; Zajacova, A. Education as "the great equalizer": Health benefits for black and white adults. Soc. Sci. Q. 2014, 95, 1064-1085. [CrossRef]

67. Navarro, V. Race or class versus race and class: Mortality differentials in the United States. Lancet 1990, 336, 1238-1240. [CrossRef]

68. Phelan, J.C.; Link, B.G.; Tehranifar, P. Social conditions as fundamental causes of health inequalities: Theory, evidence, and policy implications. J. Health Soc. Behav. 2010, 51, S28-S40. [CrossRef] [PubMed]

69. Williams, D.R.; Collins, C.U.S. Socioeconomic and racial differences in health: Patterns and explanations. Ann. Rev. Sociol. 1995, 21, 349-386. [CrossRef]

70. Kessler, R.C.; Neighbors, H.W. A new perspective on the relationships among race, social class, and psychological distress. J. Health Soc. Behav. 1986, 27, 107-115. [CrossRef] [PubMed]

71. Farmer, M.M.; Ferraro, K.F. Are racial disparities in health conditional on socioeconomic status? Soc. Sci. Med. 2005, 60, 191-204. [CrossRef] [PubMed]

72. Kaufman, J.S.; Cooper, R.S.; McGee, D.L. Socioeconomic status and health in blacks and whites: The problem of residual confounding and the resiliency of race. Epidemiology 1997, 8, 621-628. [CrossRef] [PubMed]

73. Fewell, Z.; Davey Smith, G.; Sterne, J.A. The impact of residual and unmeasured confounding in epidemiologic studies: A simulation study. Am. J. Epidemiol. 2007, 166, 646-655. [CrossRef] [PubMed]

74. Alm, A.; Wendt, L.K.; Koch, G.; Birkhed, D. Oral hygiene and parent-related factors during early childhood in relation to approximal caries at 15 years of age. Caries Res. 2008, 42, 28-36. [CrossRef] [PubMed]

75. Thomson, W.M.; Poulton, R.; Milne, B.J.; Caspi, A.; Broughton, J.R.; Ayers, K.M.S. Socioeconomic inequalities in oral health in childhood and adulthood in a birth cohort. Commun. Dent. Oral Epidemiol. 1992, 32, $345-353$. [CrossRef] [PubMed]

76. Vann, W.F., Jr.; Lee, J.Y.; Baker, D.; Divaris, K. Oral health literacy among female caregivers: Impact on oral health outcomes in early childhood. J. Dent. Res. 2010, 89, 1395-1400. [CrossRef] [PubMed]

77. Guarnizo-Herreño, C.C.; Wehby, G.L. Explaining racial/ethnic disparities in children's dental health: A decomposition analysis. Am. J. Public Health 2012, 102, 859-866. [CrossRef] [PubMed]

78. Kelly, S.E.; Binkley, C.J.; Neace, W.P.; Gale, B.S. Barriers to care-seeking for children's oral health among low-income caregivers. Am. J. Public Health 2005, 95, 1345-1351. [CrossRef] [PubMed]

79. Atchison, K.A.; Gironda, M.W.; Messadi, D.; Der-Martirosian, C. Screening for oral health literacy in an urban dental clinic. J. Public Health Dent. 2010, 70, 269-275. [CrossRef] [PubMed] 
80. Hunter, L.P.; Yount, S.M. Oral Health and Oral Health Care Practices Among Low-Income Pregnant Women. J. Midwifery Women's Health 2011, 56, 103-109. [CrossRef] [PubMed]

81. Gee, G.C.; Ford, C.L. Structural racism and health inequities: Old Issues, New Directions. Du Bois Rev. 2011, 8, 115-132. [CrossRef] [PubMed]

82. Krieger, N. Methods for the scientific study of discrimination and health: An ecosocial approach. Am. J. Public Health 2012, 102, 936-944. [CrossRef] [PubMed]

83. Williams, D.R.; Mohammed, S.A. Racism and health I: Pathways and scientific evidence. Am. Behav. Sci. 2013, 57, 1152-1173. [CrossRef] [PubMed]

84. Williams, D.R.; Mohammed, S.A. Racism and health II: A needed research agenda for effective interventions. Am. Behav. Sci. 2013, 57, 1200-1226. [CrossRef] [PubMed]

85. Williams, D.R.; Purdie-Vaughns, V. Needed Interventions to Reduce Racial/Ethnic Disparities in Health. J. Health Politics Policy Law 2016, 41, 627-651. [CrossRef] [PubMed]

86. Williams, D.R.; Mohammed, S.A.; Leavell, J.; Collins, C. Race, socioeconomic status, and health: Complexities, ongoing challenges, and research opportunities. Ann. N. Y. Acad. Sci. 2010, 1186, 69-101. [CrossRef] [PubMed]

87. Williams, D.R.; Priest, N.; Anderson, N.B. Understanding associations among race, socioeconomic status, and health: Patterns and prospects. Health Psychol. 2016, 35, 407-411. [CrossRef] [PubMed]

88. Marcenes, W.; Kassebaum, N.J.; Bernabé, E.; Flaxman, A.; Naghavi, M.; Lopez, A.; Murray, C.J. Global burden of oral conditions in 1990-2010: A systematic analysis. J. Dent. Res. 2013, 92, 592-597. [CrossRef] [PubMed]

89. Kassebaum, N.J.; Smith, A.G.C.; Bernabé, E.; Fleming, T.D.; Reynolds, A.E.; Vos, T.; Murray, C.J.L.; Marcenes, W.; GBD 2015 Oral Health Collaborators. Global, regional, and national prevalence, incidence, and disability-adjusted life years for oral conditions for 195 countries, 1990-2015: A systematic analysis for the global burden of diseases, injuries, and risk factors. J. Dent. Res. 2017, 96, 380-387. [PubMed]

(C) 2018 by the author. Licensee MDPI, Basel, Switzerland. This article is an open access article distributed under the terms and conditions of the Creative Commons Attribution (CC BY) license (http:/ / creativecommons.org/licenses/by/4.0/). 